\title{
Cation-Specific Effects on the Self-Assembly of Collagen Molecules Mediated by Acetate on Mica Surface Observed with Atomic Force Microscopy
}

\author{
Zhiwei Wang, ${ }^{1}$ Qi Xiao, ${ }^{1}$ Xuan Song, ${ }^{1}$ Yunfei Wan, ${ }^{1}$ and Jie Zhu ${ }^{1,2,3}$ \\ ${ }^{1}$ Laboratory of Agricultural and Food Biomechanics, Institute of Biophysics and College of Science, Northwest A\&F University, \\ Yangling, Shaanxi 712100, China \\ ${ }^{2}$ Sino-US Joint Research Center of Food Safety, College of Food Science and Engineering, Northwest A\&F University, Yangling, \\ Shaanxi 712100, China \\ ${ }^{3}$ Department of Animal Sciences, College of Agriculture, Purdue University, West Lafayette, IN 47907, USA
}

Correspondence should be addressed to Jie Zhu; jiezhu@nwafu.edu.cn

Received 12 July 2017; Accepted 11 October 2017; Published 6 November 2017

Academic Editor: Jesús Lozano

Copyright (C) 2017 Zhiwei Wang et al. This is an open access article distributed under the Creative Commons Attribution License, which permits unrestricted use, distribution, and reproduction in any medium, provided the original work is properly cited.

The well-organized collagen layers on mica surface have drawn extensive attention for its essential applications and studies on the process of self-assembly as a model system. In this work, collagen extracted from fish scales by acid-base method was used to explore the self-assembly characters, and atomic force microscopy was applied to observe the collagen assembled on mica surface mediated by acetate with four different cations, including $\mathrm{K}^{+}, \mathrm{Na}^{+}, \mathrm{Mg}^{2+}$, and $\mathrm{Ca}^{2+}$. It showed that cations might influence the interaction between collagen fibrils and mica surface at high ionic concentration. And a similar network structure was acquired with uniform pore size for four kinds of acetates; nearly ranged collagen fibrils in the same direction were collected in $\mathrm{Mg}^{2+}$ solutions, while flat films with some fibrils were achieved in $\mathrm{K}^{+}$solutions. The Hofmeister series and Collins' model were adapted to explain the effects of cations and acetate on the self-assembly of collagen. These results and analysis would be helpful for directing the pattern of collagen assembly on a solid surface with a potential application in food science and engineering.

\section{Introduction}

At present, collagen is widely added to the productions with high recognition and brilliant effective in cosmetic and functional food. And the collagen scaffolds were used for hemicorneal reconstruction and regeneration. Collagen is a natural protein composed of glycine, alanine, proline, and 16 other kinds of amino acids; its molecular structure is rich in $\mathrm{N}-\mathrm{H}, \mathrm{C}=\mathrm{O}$, and $-\mathrm{OH}$ and other coordination groups which can be crosslinked with some metal ions [1]. Using transmission electron microscopy to determine three-dimensional organization and collagen fibril size has been reported. And collagen extracted forms are subjected to enhance their stability by chemical crosslinking. It has been found that collagen peptide fibers can radially self-assemble after being triggered by metals [2]. A new adsorbent can be prepared by loading Zr (IV) and Fe (III) onto collagen fibers [3]. 20-40 nm clusters can be formed between collagen fibrils after being crosslinked with $\mathrm{Cr}^{3+}$, but cycle structure of collagen did not change [4]. In this article, the effects of four acetates (KAc, $\mathrm{NaAc}, \mathrm{MgAc}_{2}$, and $\mathrm{CaAc}_{2}$ ) were studied on the collagen assembly. Hofmeister series and Collins' model were used to explain the results.

In 1920s, the order of efficiency was followed by some cations as salting-out agents [5]; the order was expressed as $\mathrm{K}^{+}>\mathrm{Na}^{+}>\cdots>\mathrm{Mg}^{2+}>\mathrm{Ca}^{2+}$ after more than eighty years $[6,7]$. The numbers of papers involved in Hofmeister series related to various fields especially biomedicine are large and still keep growing every year [8-10]. Wang et al. demonstrated a sequence $\left(\mathrm{SO}_{4}{ }^{2-}>\mathrm{Ac}^{-}>\mathrm{Cl}^{-}\right)$which has the stabilizing and salting-out effects on proteins and macromolecules [11]. Acetate was selected to investigate the effect of cations on 
collagen self-assembly in this study. However the results in this experiment was not fully carried out with the law especially $\mathrm{Ca}^{2+}\left(\mathrm{K}^{+}>\mathrm{Na}^{+}>\cdots>\mathrm{Mg}^{2+}>\mathrm{Ca}^{2+}\right)$, and the ionspecific interactions in the water [12-15] need to be explained.

In this study, collagen was extracted from fish scales by acid-base method and purified by dialysis. At the same time, collagen is a natural extract that can form film because of its molecules self-assembly [16-20]. Furthermore, to make the collagen film more controllable and stable, the metal ions were used to regulate the self-assembly of collagen molecules [21]. It can provide reference for products of cosmetic and food additions.

\section{Materials and Methods}

2.1. Materials and Chemical Reagents. Live grass carp (Ctenopharyngodon idellus) was purchased from a supermarket in Yangling City, Shaanxi, China. Grass carp scales were manually removed from the fish and washed with fresh water. The harvested scales were stored in polyethylene bags at $4^{\circ} \mathrm{C}$ until experimentation. Potassium acetate, magnesium acetate tetrahydrate, and acetic acid (36\%) were purchased from Guangdong Chemical Reagent Engineering-Technological Research and Development Center (Guangdong, China). Calcium acetate monohydrate and sodium acetate trihydrate were purchased from Chengdu Kelong Chemical Reagent Factory (Chengdu, China). All reagents in analytical grade were used as received without further purification. All solutions were prepared with deionized water supplied by the Northwest A\&F University. The mica substrate $\left[\mathrm{KAl}_{2}\left(\mathrm{AlSi}_{3}\right)\right.$ $\left.\mathrm{O}_{10}(\mathrm{OH})_{2}\right]$ was purchased from Tosai (Hong Kong).

2.2. Preparation of ASC from the Scales of Grass Carp. Acidsoluble collagen (ASC) from the scales was isolated following the reported methods in reference [22] with some modifications. All steps to equip ASC were prosecuted at room temperature $\left(22-24^{\circ} \mathrm{C}\right)$. In detail, the scales of grass carp were drought in an automatic blast drying oven and then immersed in 20 volumes of $0.5 \mathrm{M} \mathrm{Na} \mathrm{CO}_{3}$ with a magnetic stirring for $3 \mathrm{~h}$, and the operation was repeated three times. After filtrating by cheesecloth, the insoluble components were rinsed with deionized water until a neutral $\mathrm{pH}$ was reached. The insoluble components were reimmersed in $0.3 \mathrm{M}$ EDTA for $12 \mathrm{~h}$. After rinsing to neutral $\mathrm{pH}$, the insoluble components were reimmersed in 40 volumes of $0.5 \mathrm{M}$ acetic acid using a magnetic stirring for $24 \mathrm{~h}$ and repeated again. Both of the supernatants were collected and merged as the original ASC solution. The $\mathrm{NaCl}$ was added to the ASC original solution to a salt concentration of $0.9 \mathrm{M}$. The collagen precipitation would be salted out for 24 hours and then redissolved completely with $0.5 \mathrm{M}$ acetic acid. Then, the collagen solution was dialyzed with $0.1 \mathrm{M}$ acetic acid and deionized water for $12 \mathrm{~h}$, respectively. The ASC supernatant was lyophilized into solid and then stored at $4^{\circ} \mathrm{C}$ for further experiment.

2.3. Preparation of Collagen Solution for AFM Imaging. $1 \%$ acetic acid at $\mathrm{pH} 2.8$ was used as the solvent to dissolve collagen solutions and diverse acetate solutions. Collagen was dissolved in $1 \%$ acetic acid solution to obtain $5.0 \mathrm{mg} / \mathrm{mL}$ collagen solution which was further diluted to prepare other collagen solutions in different concentrations. All of solutions were stored at $4^{\circ} \mathrm{C}$ for next experiment. Original acetate solutions in $5.0 \mathrm{M}$ were used to dilute metal salts to various concentrations for further use. $10 \mu \mathrm{L}$ collagen solution with different cations was deposited onto the freshly cleaved mica sheets in $1.0 \times 0.5 \mathrm{~cm}^{2}$, respectively, and was dried in sealed desiccators at room temperature $\left(15-20^{\circ} \mathrm{C}\right)$. Then, the mica sheets were fixed onto the sample mounting disk in diameter of $12 \mathrm{~mm}$ for AFM imaging.

2.4. AFM Imaging of Collagen Assembly. A Multimode-8 AFM (Bruker Co., Santa Barbara, USA) was employed in ScanAsyst mode with ScanAsyst-AIR probes for topology of collagen assembly at $0.977 \mathrm{~Hz}$. Typical height images, roughness, and surface area difference were statistically analyzed using the offline software NanoscopeAnalysis V1.10 (Bruker Co., Santa Barbara, USA). Root mean square roughness $(\mathrm{Rq})$ and average roughness $(\mathrm{Ra})$ were collected to describe the topological change, and the surface area difference was gathered to indicate the degree of surface coverage which was named the difference between the analyzed region's threedimensional surface area and its two-dimensional, projected area.

\section{Results and Discussion}

3.1. Self-Assembly of Collagen in Different Collagen Concentration. Typical AFM height images of collagen assembly on mica in different collagen concentrations were shown in Figure 1. It was shown that the morphology of self-assembled collagen in different concentrations has a significant difference. Section profiles of height images, roughness ( $\mathrm{Ra}, \mathrm{Rq})$, and surface area difference were shown in Table 1 . At $5 \mu \mathrm{g} / \mathrm{mL}$, the collagen molecules were self-assembled into single fibers on the mica sheet with the width of $16 \pm 4 \mathrm{~nm}$ and the height of $1.027 \pm 0.055 \mathrm{~nm}$, and Ra was $0.142 \mathrm{~nm}$, Rq was $0.188 \mathrm{~nm}$, and surface area difference was $0.311 \%$ (Figure $1(\mathrm{a})$ ). Then, the length of collagen fibers was gradually increased and interwoven into porous network structure with the width of $27 \pm 9 \mathrm{~nm}$, the height of $1.165 \pm 0.077 \mathrm{~nm}$, and Ra of $0.233 \mathrm{~nm}$, $\mathrm{Rq}$ of $0.317 \mathrm{~nm}$, and surface area difference of $0.313 \%$ (Figure 1(b)). At low concentrations, single fibers were the mainly self-assembled morphology of collagen molecules. Collagen fibers got thicker and crosslinked on the mica sheet with each other at the width of $41 \pm 15 \mathrm{~nm}$, the height of $1.462 \pm 0.030 \mathrm{~nm}$, $\mathrm{Ra}$ of $0.296 \mathrm{~nm}, \mathrm{Rq}$ of $0.364 \mathrm{~nm}$, and surface area difference of $0.340 \%$ at $20 \mu \mathrm{g} / \mathrm{mL}$ (Figure $1(\mathrm{c})$ ). After the concentration of collagen was increased to $50 \mu \mathrm{g} / \mathrm{mL}$, collagen molecules arranged evenly just like rough film on the mica sheet with the width of $42 \pm 9 \mathrm{~nm}$, the height of $1.923 \pm 0.168 \mathrm{~nm}$, Ra of $0.385 \mathrm{~nm}, \mathrm{Rq}$ of $0.493 \mathrm{~nm}$, and surface area difference of $0.662 \%$ which was much higher than other concentrations (Figure 1(d)). The porous structure was observed in the range of $2 \times 2 \mu \mathrm{m}$, as shown in Figure 1(d). There was large difference in height and white particles caused by large local concentration. It was not suitable for observing the details of the self-assembled collagen morphology. So the $20 \mu \mathrm{g} / \mathrm{mL}$ 

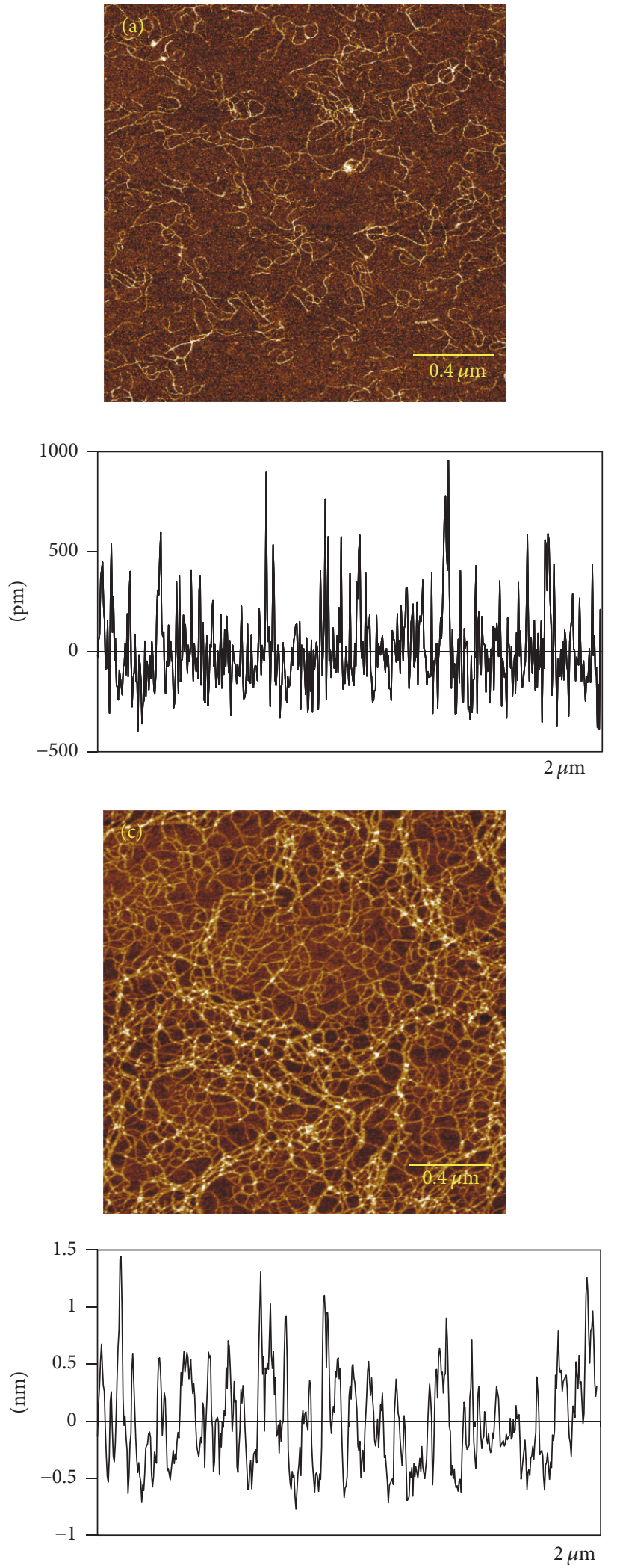
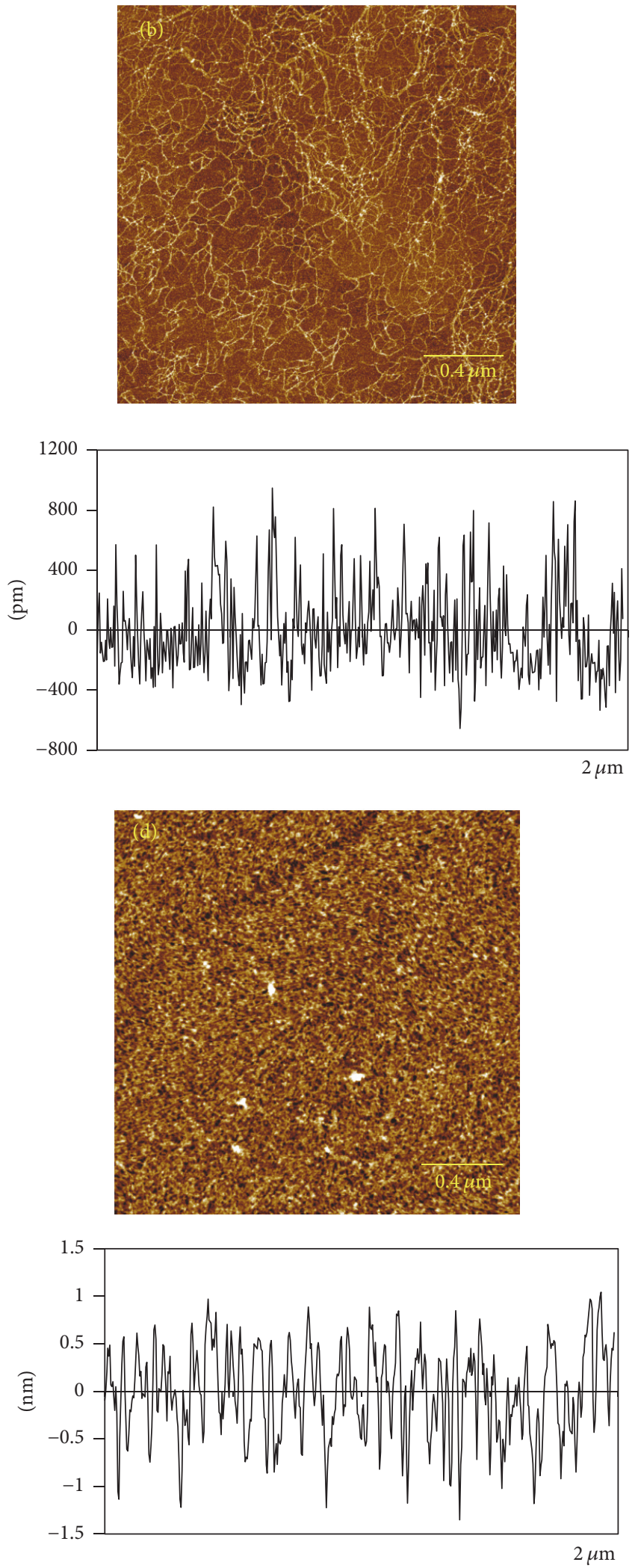

Figure 1: Typical AFM height images of collagen fibrils assembled on mica surface at different concentrations of collagen: (a) 5, (b) 10, (c) 20 , and (d) $50 \mu \mathrm{g} / \mathrm{mL}$. Scale bar $=0.4 \mu \mathrm{m}$. 
TABLE 1: Width, height, roughness ( $\mathrm{Ra}, \mathrm{Rq})$, and surface area difference of the collagen molecular self-assembly in different collagen, KAc, $\mathrm{NaAc}, \mathrm{MgAc}_{2}$, and $\mathrm{CaAc}_{2}$ concentrations.

\begin{tabular}{ccccccc}
\hline Cation & Concentration & Width/nm & Height/nm & $\mathrm{Ra} / \mathrm{nm}$ & $\mathrm{Rq} / \mathrm{nm}$ & Surface area difference \\
\hline & $5 \mu \mathrm{g} / \mathrm{mL}$ & $16 \pm 4$ & $1.027 \pm 0.055$ & 0.142 & 0.188 & $0.311 \%$ \\
& $10 \mu \mathrm{g} / \mathrm{mL}$ & $27 \pm 9$ & $1.165 \pm 0.077$ & 0.233 & 0.317 & $0.313 \%$ \\
& $20 \mu \mathrm{g} / \mathrm{mL}$ & $41 \pm 15$ & $1.462 \pm 0.030$ & 0.296 & 0.364 & $0.340 \%$ \\
& $50 \mu \mathrm{g} / \mathrm{mL}$ & $42 \pm 9$ & $1.923 \pm 0.168$ & 0.385 & 0.493 & $0.662 \%$ \\
\hline \multirow{4}{*}{$\mathrm{K}^{+}$} & $25 \mathrm{mM}$ & $49 \pm 7$ & $1.906 \pm 0.104$ & 0.489 & 0.572 & $0.412 \%$ \\
& $50 \mathrm{mM}$ & $60 \pm 24$ & $1.413 \pm 0.098$ & 0.369 & 0.442 & $0.163 \%$ \\
& $100 \mathrm{mM}$ & $95 \pm 19$ & $2.279 \pm 0.029$ & 0.651 & 0.781 & $0.275 \%$ \\
$\mathrm{Na}^{+}$ & $300 \mathrm{mM}$ & $73 \pm 30$ & $3.349 \pm 0.352$ & 0.999 & 1.210 & $0.388 \%$ \\
& $50 \mathrm{mM}$ & $24 \pm 4$ & $1.302 \pm 0.252$ & 0.264 & 0.349 & $0.633 \%$ \\
& $100 \mathrm{mM}$ & $27 \pm 4$ & $1.397 \pm 0.449$ & 0.289 & 0.360 & $0.388 \%$ \\
$\mathrm{Mg}^{2+}$ & $200 \mathrm{mM}$ & $46 \pm 14$ & $2.817 \pm 0.170$ & 0.591 & 0.743 & $0.625 \%$ \\
& $400 \mathrm{mM}$ & $45 \pm 8$ & $1.401 \pm 0.084$ & 0.378 & 0.471 & $0.179 \%$ \\
\hline & $50 \mathrm{mM}$ & $43 \pm 10$ & $2.378 \pm 0.078$ & 0.544 & 0.188 & $0.501 \%$ \\
$\mathrm{Ca}^{2+}$ & $100 \mathrm{mM}$ & $76 \pm 14$ & $2.665 \pm 0.058$ & 0.643 & 0.317 & $0.594 \%$ \\
& $300 \mathrm{mM}$ & $81 \pm 5$ & $2.435 \pm 0.143$ & 0.604 & 0.364 & $0.208 \%$ \\
& $400 \mathrm{mM}$ & $59 \pm 17$ & $2.056 \pm 0.048$ & 0.441 & 0.493 & $0.634 \%$ \\
\hline
\end{tabular}

collagen solution was selected to study the impact of metal ions.

\subsection{Effect of KAc on Self-Assembly of Collagen Molecules.} To investigate the effect of cation concentration, $20 \mathrm{uL}$ of $20 \mathrm{ug} / \mathrm{mL}$ collagen solutions in five different KAc concentrations $(25,50,100,300$, and $500 \mathrm{mM})$ was deposited onto the fresh cleaved mica sheet and used for AFM imaging after drying in the air. Typical AFM height images of collagen fibrils assembled on mica surface at $20 \mathrm{ug} / \mathrm{mL}$ collagen in the presence of different concentrations of KAc were shown in Figure 2. Section profiles of height images, roughness ( $\mathrm{Ra}$, $\mathrm{Rq}$ ), and surface area difference were shown in Table 1 . In the presence of $25 \mathrm{mM}$ KAc, fibril-like collagen mesh was formed on mica surface with the width of $49 \pm 7 \mathrm{~nm}$ and the height of $1.906 \pm 0.104 \mathrm{~nm}$. Ra was $0.489 \mathrm{~nm}, \mathrm{Rq}$ was $0.572 \mathrm{~nm}$, and surface area difference was $0.412 \%$ (Figure $2(\mathrm{a})$ ). And the mesh pore had less difference in size which on average was $1.906 \mathrm{~nm}$, as shown in Figure 2(a). Instead of the fibril-like collagen mesh at $25 \mathrm{mM} \mathrm{KAc}$, the root-like collagen fibrils were shown at higher KAc concentrations and changed from straight alignment at $50 \mathrm{mM}$ to regular assembly at $100 \mathrm{mM}$ KAc in detail. The fibers overlap to root-like structure with numerous branches at a diameter of $26 \mathrm{~nm}$ and the width was $60 \pm 24 \mathrm{~nm}$ and the height was $1.413 \pm 0.098 \mathrm{~nm}$. Ra was $0.369 \mathrm{~nm}, \mathrm{Rq}$ was $0.442 \mathrm{~nm}$, and surface area difference was $0.163 \%$ at $50 \mathrm{mM} \mathrm{KAc} \mathrm{(Figure} \mathrm{2(b)).} \mathrm{Then} \mathrm{the} \mathrm{pluralities} \mathrm{of}$ fibers are aggregated in fibrous bundles with a diameter of $38-138 \mathrm{~nm}$ and fibers were $1.46-5.31$ thicker than at $25 \mathrm{mM}$ KAc (Figure 2(c)). The width was $95 \pm 19 \mathrm{~nm}$, the height was $2.279 \pm 0.029 \mathrm{~nm}$, Ra was $0.651 \mathrm{~nm}, \mathrm{Rq}$ was $0.781 \mathrm{~nm}$, and surface area difference was $0.275 \%$ at $100 \mathrm{mM}$ KAc. The numbers of dispersed collagen fibers were significantly increased and the porous network was reconstructed instead of the fiber bundles (Figure 2(d)). The width was $73 \pm 30 \mathrm{~nm}$, the height was $3.349 \pm 0.352 \mathrm{~nm}$, Ra was $0.999 \mathrm{~nm}$, Rq was $1.210 \mathrm{~nm}$, and surface area difference was $0.388 \%$ at $300 \mathrm{mM}$ KAc. It was shown that the collagen molecules assembled into the fibrous network on the mica sheet at low concentrations, the fibers gathered into bundles with the increase of the concentration, and the salinity had a great influence at high concentrations.

3.3. Effect of NaAc on Self-Assembly of Collagen Molecules. AFM images of collagen assemblies on mica surface in the presence of various concentration of $\mathrm{NaAc}(50,100$, 200, and $400 \mathrm{mM}$ ) were shown in Figure 3. Section profiles of height images, roughness ( $\mathrm{Ra}, \mathrm{Rq})$, and surface area difference were shown in Table 1 . In the presence of $50 \mathrm{mM}$ $\mathrm{NaAc}$, it was clearly observed that the collagen fibers were evenly distributed on the mica surface with the width of $24 \pm 4 \mathrm{~nm}$ and the height of $1.302 \pm 0.252 \mathrm{~nm}$, and Ra was $0.264 \mathrm{~nm}, \mathrm{Rq}$ was $0.349 \mathrm{~nm}$, and surface area difference was $0.633 \%$ (Figure 3(a)). Then the collagen fibers were woven into beautiful pattern of flowers with uniform pores at the width of $27 \pm 4 \mathrm{~nm}$, the height of $1.397 \pm 0.449 \mathrm{~nm}$, Ra of $0.289 \mathrm{~nm}, \mathrm{Rq}$ of $0.360 \mathrm{~nm}$, and surface area difference of $0.388 \%$ at $100 \mathrm{mM} \mathrm{NaAc}$ (Figure 3(b)). When it came to $200 \mathrm{mM} \mathrm{NaAc}$, the multilayers of fibrils assembled on the basis of dense porous mesh organized on the mica sheet with the width of $46 \pm 14 \mathrm{~nm}$ and the height of $2.817 \pm$ $0.170 \mathrm{~nm}$, and Ra was $0.591 \mathrm{~nm}, \mathrm{Rq}$ was $0.743 \mathrm{~nm}$, and surface 

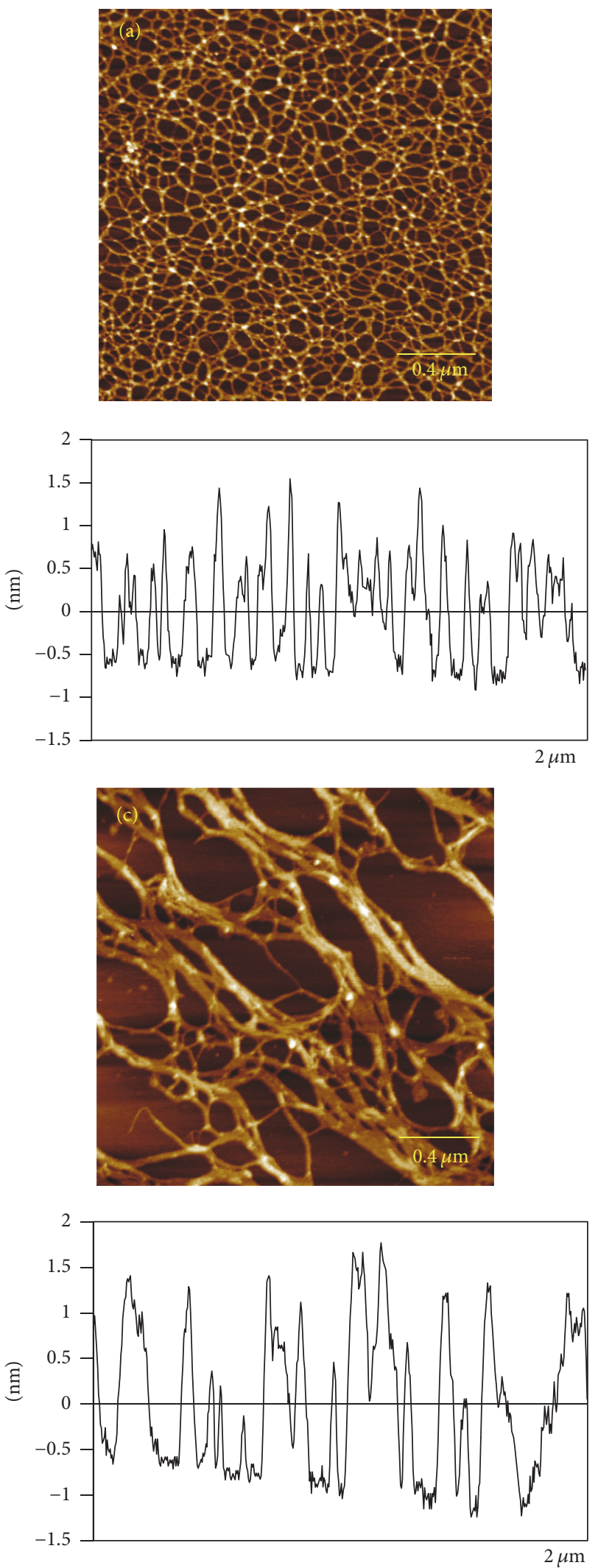
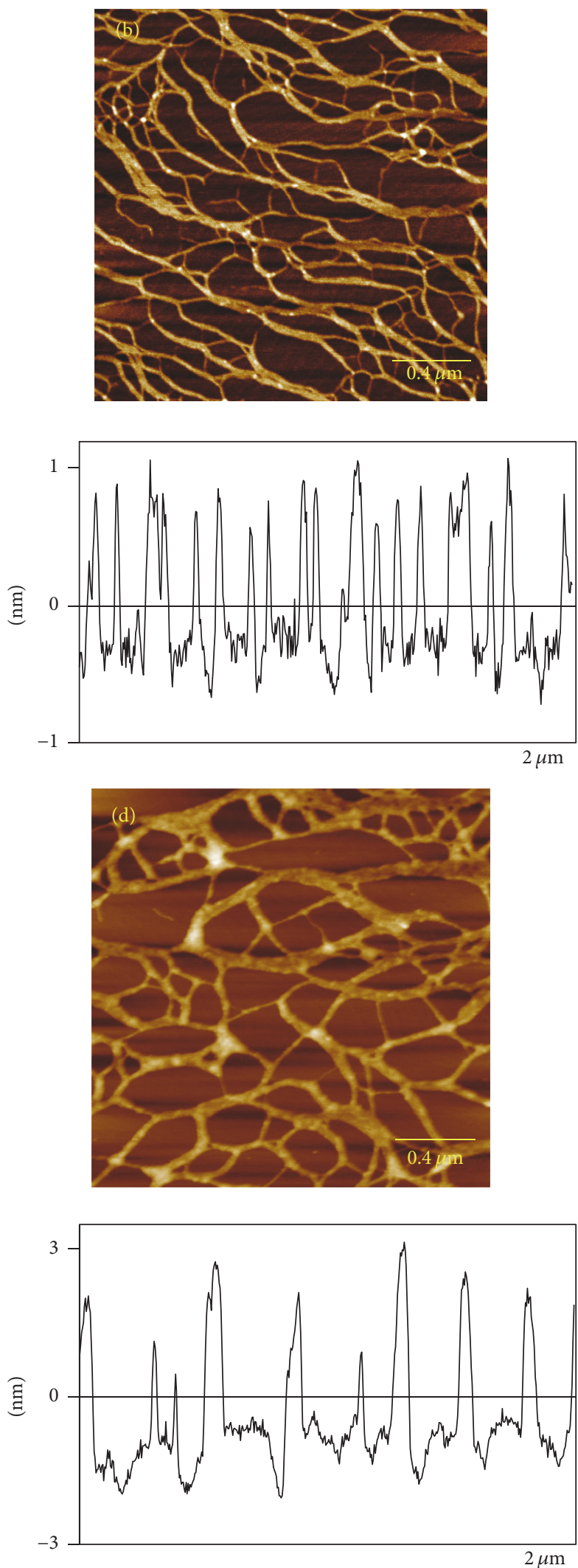

FIGURE 2: Typical AFM height images of collagen fibrils assembled on mica surface at $20 \mu \mathrm{g} / \mathrm{mL}$ collagen in the presence of different concentrations of KAc: (a) 25, (b) 50, (c) 100, and (d) $300 \mathrm{mM}$. Scale bar $=0.4 \mu \mathrm{m}$. 

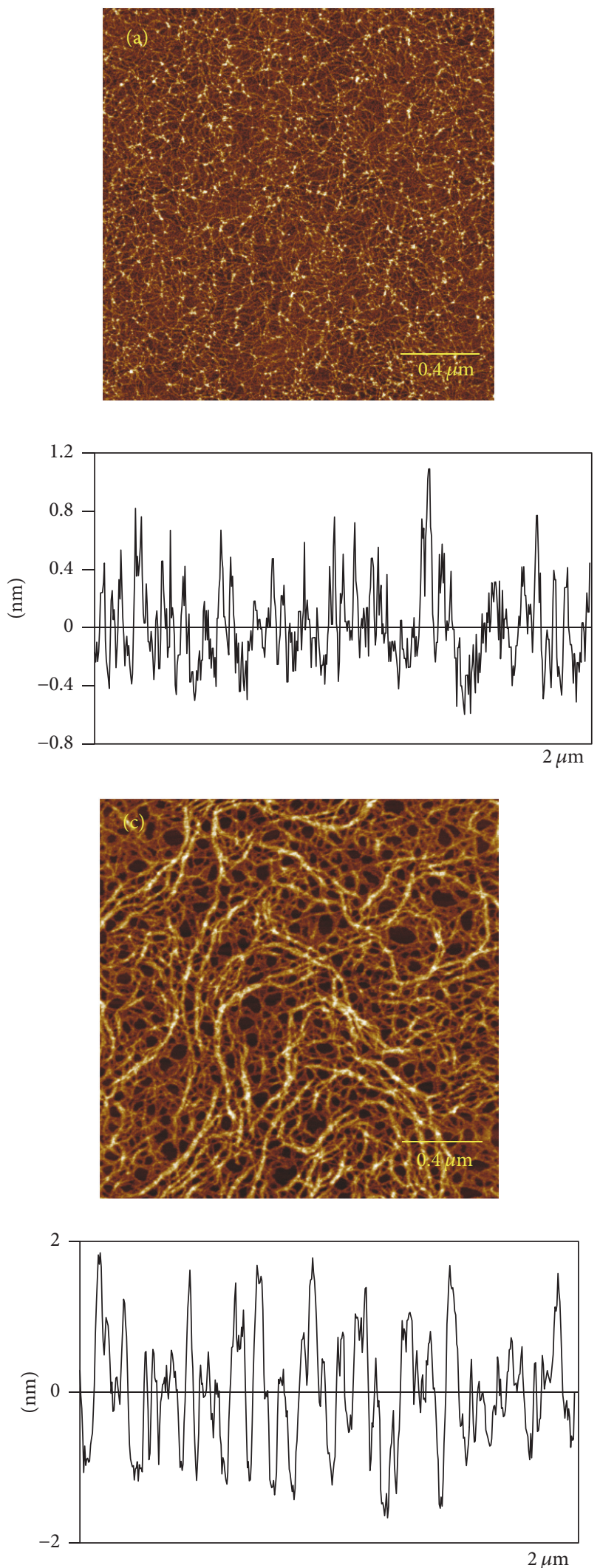
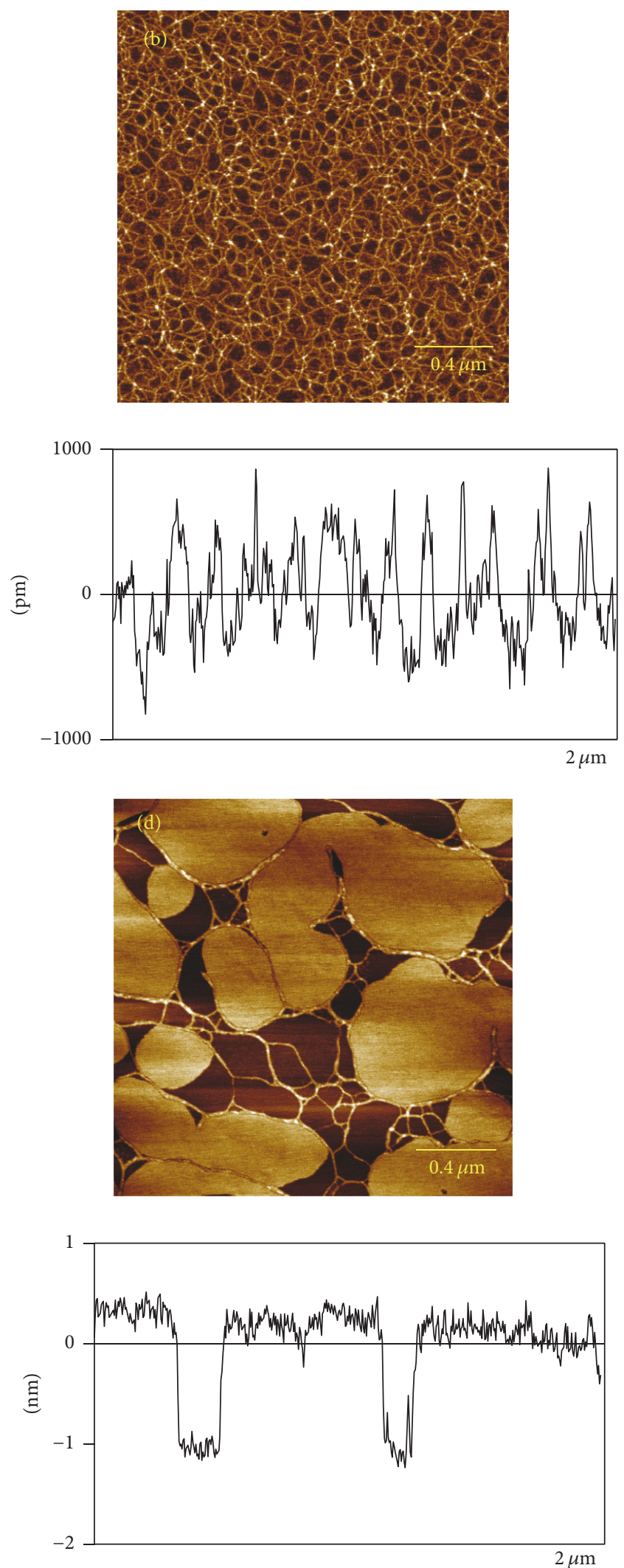

FIGURE 3: Typical AFM height images of collagen fibrils assembled on mica surface at $20 \mu \mathrm{g} / \mathrm{mL}$ collagen in the presence of different concentration of NaAc: (a) 50, (b) 100, (c) 200, and (d) $400 \mathrm{mM}$. Scale bar $=0.4 \mu \mathrm{m}$. 
area difference was $0.625 \%$ (Figure 3(c)). At $400 \mathrm{mM} \mathrm{NaAc}$, smooth, flat, and flaky membrane appeared with fibers (the width was $45 \pm 8 \mathrm{~nm}$ ) attaching at the film thickness of $1.401 \pm$ $0.084 \mathrm{~nm}$ and Ra was $0.378 \mathrm{~nm}, \mathrm{Rq}$ was $0.471 \mathrm{~nm}$, and surface area difference was $0.179 \%$ which was much lower than other concentrations (Figure 3(d)). Obviously, the collagen molecules assembled into fibers or multilayer fibers on the mica sheet at the low concentrations, and flat membrane at higher concentrations. It demonstrated that the solubility of collagen increased with the $\mathrm{NaAc}$ concentration; that is, collagen stability was becoming weaker and completely denatured when the collagen films emerged.

3.4. Effect of $\mathrm{MgAc}_{2}$ on Self-Assembly of Collagen Molecules. The effect of four $\mathrm{MgAc}_{2}$ concentrations (50, 100, 300, and $400 \mathrm{mM}$ ) on $20 \mu \mathrm{g} / \mathrm{mL}$ collagen self-assembly is shown in Figure 4. Section profiles of height images, roughness (Ra, $\mathrm{Rq}$ ), and surface area difference were shown in Table 1 . In the presence of $50 \mathrm{mM} \mathrm{MgAc}$, the porous network can be clearly observed on the mica sheet and it had strong directionality making the pores elliptical. The width was 43 $\pm 10 \mathrm{~nm}$, the height was $2.378 \pm 0.078 \mathrm{~nm}$, Ra was $0.544 \mathrm{~nm}$, Rq was $0.188 \mathrm{~nm}$, and surface area difference was $0.501 \%$ at $50 \mathrm{mM} \mathrm{MgAc}_{2}$ (Figure 4(a)). The collagen molecules were assembled into dense fiber mesh with small uniform pores at the width of $76 \pm 14 \mathrm{~nm}$ and the height of $2.665 \pm 0.058 \mathrm{~nm}$, and $\mathrm{Ra}$ was $0.643 \mathrm{~nm}, \mathrm{Rq}$ was $0.317 \mathrm{~nm}$, and surface area difference was $0.594 \%$ at $100 \mathrm{mM} \mathrm{MgAc}_{2}$ (Figure 4(b)). When the $\mathrm{MgAc}_{2}$ concentration increased to $300 \mathrm{mM}$, single fibers got thicker with consistent directionality at the width of 81 $\pm 5 \mathrm{~nm}$ and the height of $2.435 \pm 0.143 \mathrm{~nm}$, and $\mathrm{Ra}$ was $0.604 \mathrm{~nm}, \mathrm{Rq}$ was $0.364 \mathrm{~nm}$, and surface area difference was $0.208 \%$ (Figure $4(\mathrm{c})$ ). The multilayered fibers were distributed on the mica sheet at the width of $59 \pm 17 \mathrm{~nm}$ and the height of $2.056 \pm 0.048 \mathrm{~nm}$, and Ra was $0.441 \mathrm{~nm}, \mathrm{Rq}$ was $0.493 \mathrm{~nm}$, and surface area difference was $0.634 \%$ at $400 \mathrm{mM} \mathrm{MgAc}{ }_{2}$ (Figure 4(d)). It indicated that collagen molecules assembled into dense mesh after the $\mathrm{MgAc}_{2}$ was added, which was similar to the effect of $\mathrm{NaAc}$.

3.5. Effect of $\mathrm{CaAc}_{2}$ on Self-Assembly of Collagen Molecules. The effect of six $\mathrm{CaAc}_{2}$ concentrations $(100,200,300$, and $400 \mathrm{mM}$ ) on $20 \mu \mathrm{g} / \mathrm{mL}$ collagen self-assembly was proved in Figure 5. Section profiles of height images, roughness ( $\mathrm{Ra}$, $\mathrm{Rq}$ ), and surface area difference were shown in Table 1 . In the presence of $100 \mathrm{mM} \mathrm{CaAc}_{2}$, collagen microfibers were observed on the mica sheet with the width of $38 \pm 4 \mathrm{~nm}$ and the height of $0.892 \pm 0.021 \mathrm{~nm}$, and Ra was $0.168 \mathrm{~nm}$, Rq was $0.233 \mathrm{~nm}$, and surface area difference was $0.147 \%$ at $100 \mathrm{mM}$ $\mathrm{CaAc}_{2}$ (Figure 5(a)). The collagen fibrils changed from disordered arrangement to regular network with uniform pores with the width of $47 \pm 8 \mathrm{~nm}$, the height of $1.319 \pm 0.058 \mathrm{~nm}$, $\mathrm{Ra}$ of $0.453 \mathrm{~nm}, \mathrm{Rq}$ of $0.536 \mathrm{~nm}$, and surface area difference of $0.238 \%$ at $200 \mathrm{mM} \mathrm{CaAc}_{2}$ (Figure 5(b)). When it came to $300 \mathrm{mM}$, single fibers were organized on the mica sheet with longer length at the width of $56 \pm 13 \mathrm{~nm}$ and the height of $1.378 \pm 0.068 \mathrm{~nm}$, and $\mathrm{Ra}$ was $0.346 \mathrm{~nm}$, Rq was $0.516 \mathrm{~nm}$, and surface area difference was $0.375 \%$ (Figure $5(\mathrm{c})$ ). Then the long fibers were disconnected into short ones with similar length and they gathered into bundles at the width of 58 $\pm 10 \mathrm{~nm}$ and the height of $1.083 \pm 0.111 \mathrm{~nm}$, and $\mathrm{Ra}$ was $0.222 \mathrm{~nm}, \mathrm{Rq}$ was $0.311 \mathrm{~nm}$, and surface area difference was $0.205 \%$ at $400 \mathrm{mM} \mathrm{CaAc}_{2}$ (Figure 5(d)). It was confirmed that the collagen molecules assembled into the fibrils on the mica sheet at low concentrations (Figure 5(a)); then the fibers got longer and intertwined into network at medium concentrations (Figures 5(b)-5(c)); finally they gathered into bundles and tend to be randomly dispersed at high concentrations (Figure 5(d)).

The effects of cations on the self-assembly of collagen molecules were demonstrated in four acetates. With the increase of $\mathrm{Na}^{+}$and $\mathrm{Mg}^{2+}$ concentration, the morphology of self-assembled collagen molecules changed from singlelayer structure to multilayer network or flat membrane on the mica sheet, which indicated that $\mathrm{Na}^{+}$and $\mathrm{Mg}^{2+}$ could promote the dissolution of collagen in acidic solution. Collagen molecules self-assembled into coarse fibers at low and medium concentrations and better aggregation especially at high concentrations. It was shown that $\mathrm{K}^{+}$and $\mathrm{Ca}^{2+}$ can effectively reduce the solubility of collagen and make the collagen macromolecules more stable in acidic solution.

The order of $\mathrm{K}^{+}>\mathrm{Na}^{+}>\mathrm{Mg}^{2+}>\mathrm{Ca}^{2+}$ was mentioned in Hofmeister series, which was followed on the efficiency of cations as salting-out agents. In this article, however, Collins' model was required to analyze it which did not fully comply with $\mathrm{Ca}^{2+}$. At the atomic level, $\mathrm{Ca}^{2+}$ has a larger radius than $\mathrm{Na}^{+}$and $\mathrm{Mg}^{2+}$; there would be a bigger amount of water molecules combined with $\mathrm{Ca}^{2+}$ to hydrated molecules. A large and loose hydrated shell was formed at $\mathrm{Ca}^{2+}$ outer layer, so that the two ions cannot form a close ion pair, leading to a large number of $\mathrm{Ca}^{2+}$ freely dispersed in the solution. Due to electrostatic interaction, numbers of $\mathrm{Ca}^{2+}$ were adsorbed to the protein, making hydrogen bonds greatly weakened on the polypeptide chains, and finally, the solubility of collagen was decreased.

\section{Conclusions}

The studies on the morphology and stability of collagen selfassembly in presence of four metal cations $\left(\mathrm{K}^{+}, \mathrm{Na}^{+}, \mathrm{Mg}^{2+}\right.$, and $\mathrm{Ca}^{2+}$ ) by AFM can lead to the following conclusions. The strong effect of $\mathrm{K}^{+}$on collagen self-assembly belongs to kosmotropes in the Hofmeister series, which can increase the stability of collagen. The binding of $\mathrm{K}^{+}$and $\mathrm{Ca}^{2+}$ with collagen molecules will lead to the decrease of collagen hydrogenbonding and the increase of the protein hydrophobicity; and the combination of both ions and collagen leads to a decrease in hydrophobicity on the collagen molecules. In contrast, the effects of $\mathrm{Na}^{+}$and $\mathrm{Mg}^{2+}$ on collagen selfassembly were typically chaotropic and will cause collagen assembly homogeneous dense network or flat membrane and the increase of collagen solubility. In this study, Hofmeister series [11] and Collins' model [12-15] were used to explain the interaction mechanism of collagen and different cations at the molecular level. It provides theoretical guidance and data supports for the biological, medical, food, and cosmetic manufacturing industries. 

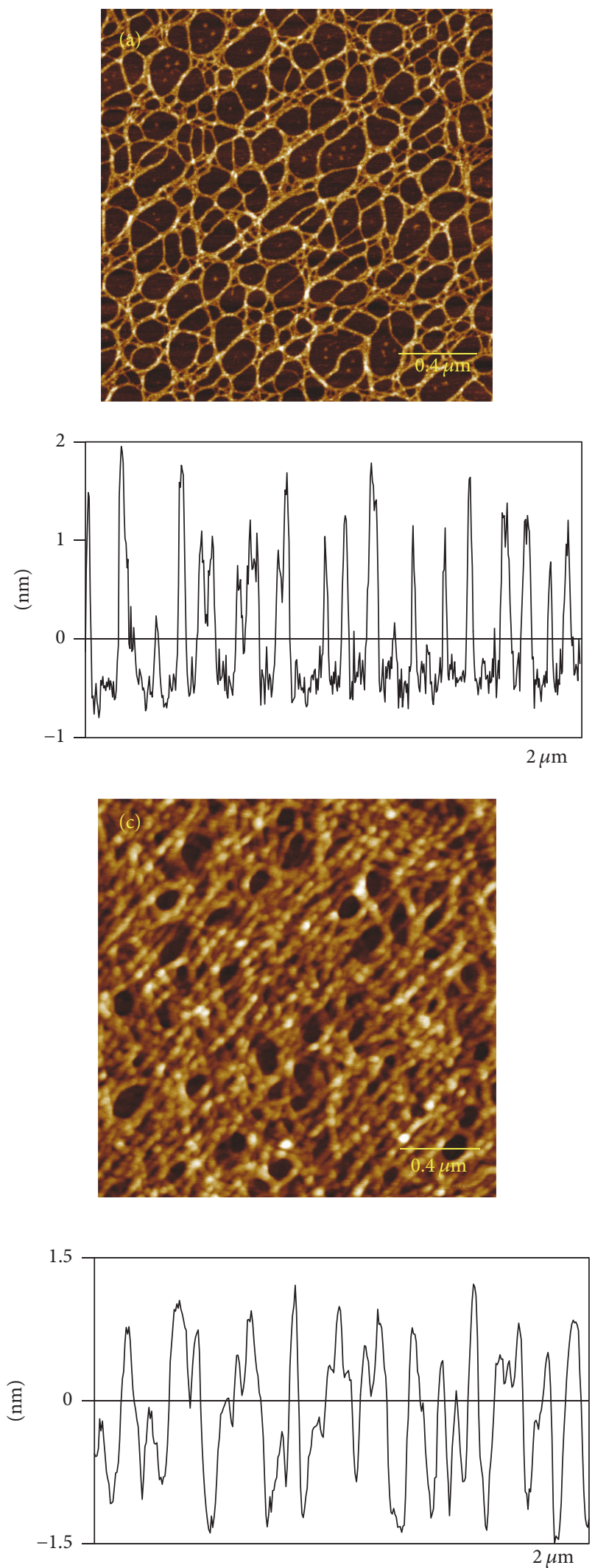
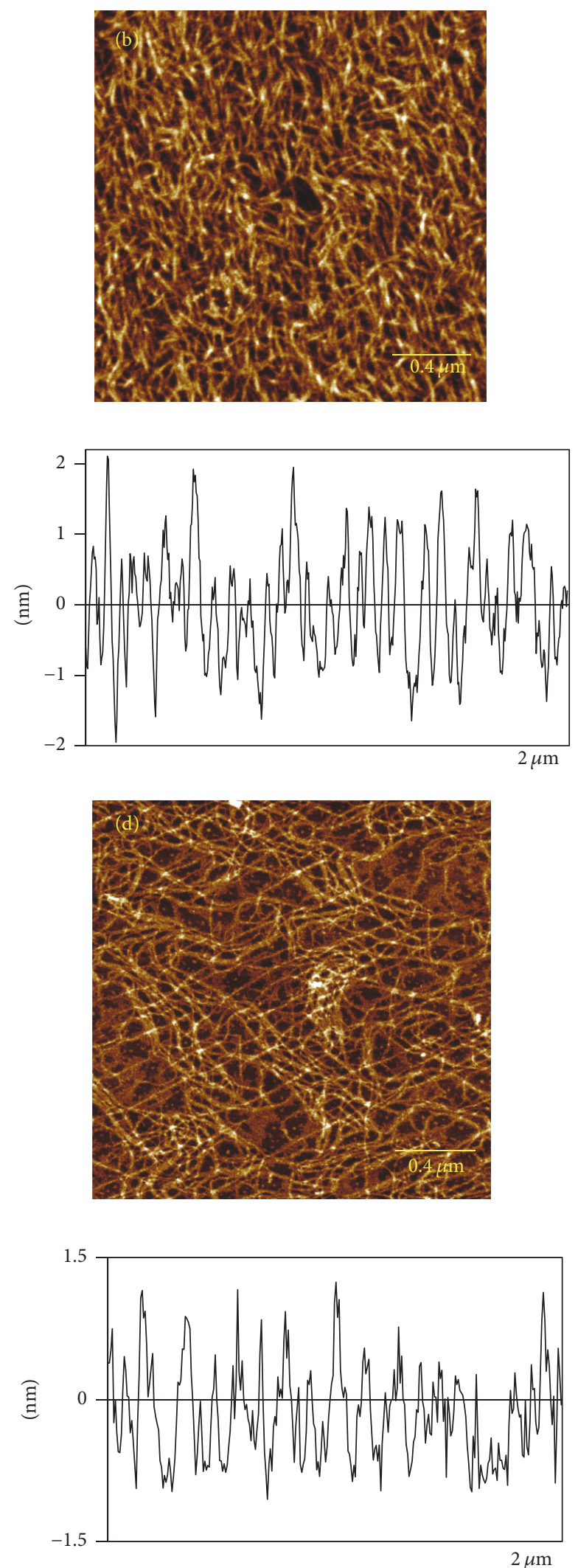

FIGURE 4: Typical AFM height images of collagen fibrils assembled on mica surface at $20 \mu \mathrm{g} / \mathrm{mL}$ collagen in the presence of different concentration of $\mathrm{MgAc}_{2}$ : (a) 50, (b) 100, (c) 300, and (d) $400 \mathrm{mM}$. Scale bar $=0.4 \mu \mathrm{m}$. 

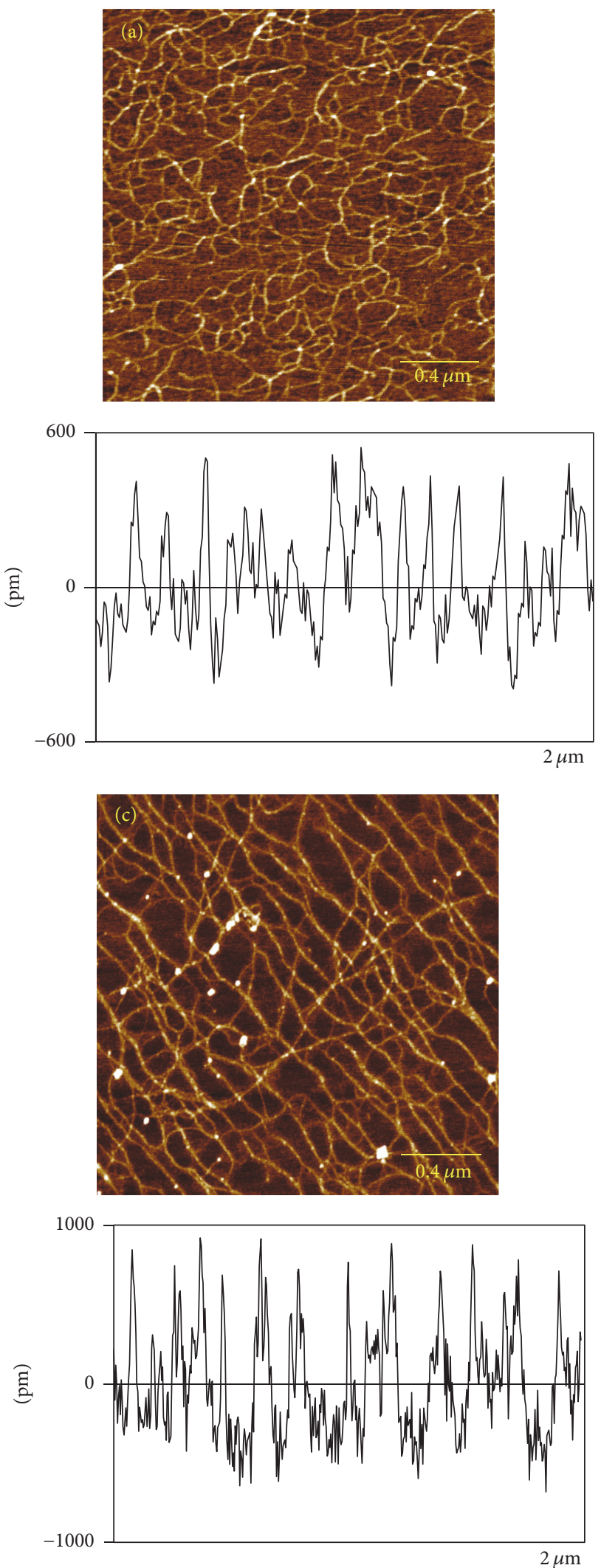
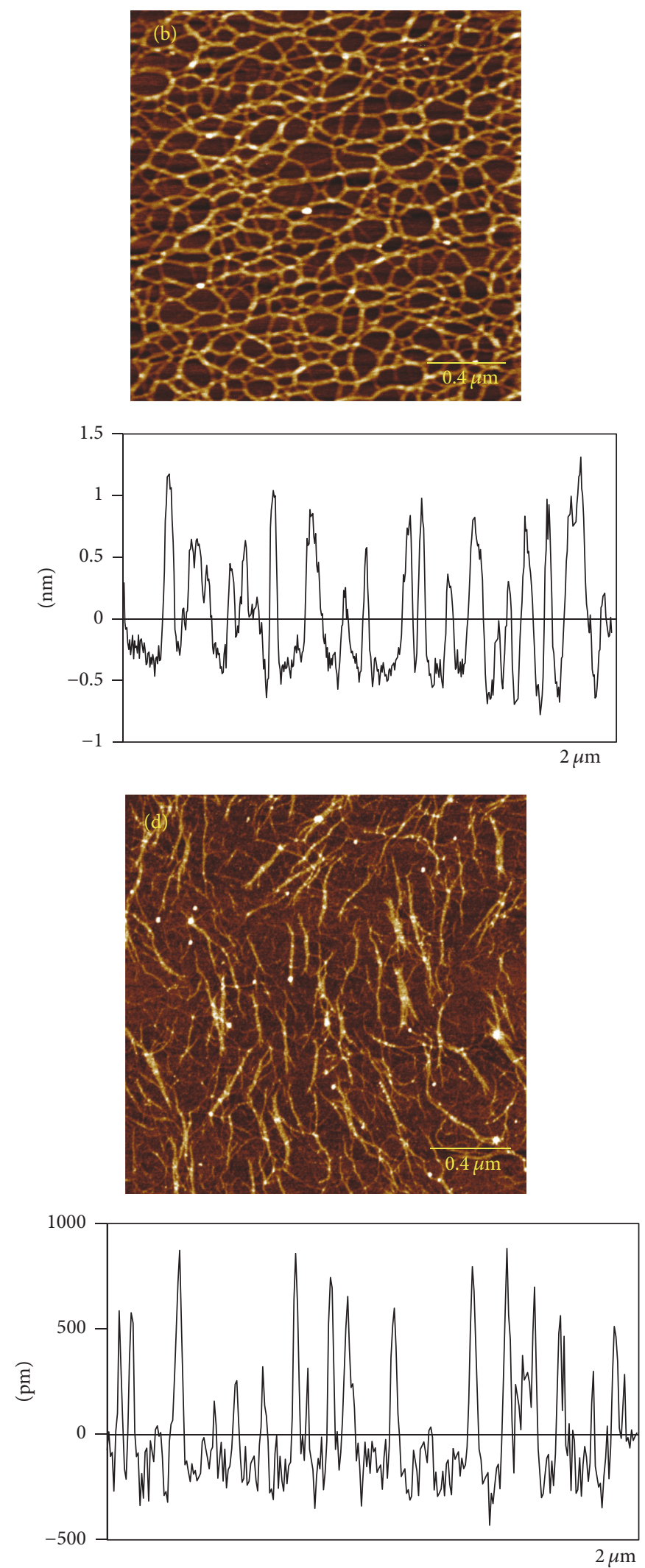

FIGURE 5: Typical AFM height images of collagen fibrils assembled on mica surface at $20 \mu \mathrm{g} / \mathrm{mL}$ collagen in the presence of different concentration of $\mathrm{CaAc}_{2}$ : (a) 100, (b) 200, (c) 300, and (d) $400 \mathrm{mM}$. Scale bar $=0.4 \mu \mathrm{m}$. 


\section{Conflicts of Interest}

The authors declare that they have no conflicts of interest.

\section{Acknowledgments}

This project was supported by International Postdoctoral Exchange Fellowship of China Postdoctoral Council (20140059, Jie Zhu), Sichuan Key Lab of Meat Processing, Chengdu University (17-R-05, Jie Zhu), International S\&T Cooperation Foundation of Northwest A\&F University (A213021505, Jie Zhu), and Shaanxi Postdoctoral Foundation (2015, Jie Zhu).

\section{References}

[1] H. Liu, Y. Xi, S. Ge, and S. Wang, "Synthesis, characterization, and antibacterial activity of collagen-metal complexes," Journal of Zhengzhou University (Medical Sciences), vol. 67, pp. 16751686.

[2] D. E. Przybyla and J. Chmielewski, "Metal-triggered radial selfassembly of collagen peptide fibers," Journal of the American Chemical Society, vol. 130, no. 38, pp. 12610-12611, 2008.

[3] B. R. Locke, M. Sato, P. Sunka, M. R. Hoffmann, and J. Chang, "Electrohydraulic discharge and nonthermal plasma for water treatment," Industrial \& Engineering Chemistry Research, vol. 45, pp. 3896-3901, 2006.

[4] B. Wu, C. Mu, G. Z. And, and W. Lin, "Effects of Cr3+ on the structure of collagen fiber," Langmuir, vol. 25, no. 19, pp. 1190511910, 2009.

[5] M. Randall and C. F. Failey, "The Activity coefficient of the undissociated part of weak electrolytes," Chemical Reviews, vol. 4, no. 3, pp. 291-318, 1927.

[6] T. Oncsik, G. Trefalt, M. Borkovec, and I. Szilagyi, "Specific ion effects on particle aggregation induced by monovalent salts within the Hofmeister series," Langmuir, vol. 31, no. 13, pp. 3799-3807, 2015.

[7] L. He, S. Cai, B. Wu, C. Mu, G. Zhang, and W. Lin, “Trivalent chromium and aluminum affect the thermostability and conformation of collagen very differently," Journal of Inorganic Biochemistry, vol. 117, pp. 124-130, 2012.

[8] P. Lo Nostro and B. W. Ninham, "Hofmeister phenomena: An update on ion specificity in biology," Chemical Reviews, vol. 112, no. 4, pp. 2286-2322, 2012.

[9] X. Tadeo, B. López-Méndez, D. Castaño, T. Trigueros, and O. Millet, "Protein stabilization and the hofmeister effect: The role of hydrophobic solvation," Biophysical Journal, vol. 97, no. 9, pp. 2595-2603, 2009.

[10] W. Kunz, J. Henle, and B. W. Ninham, “ZurLehre von der Wirkung der Salze' (about the science of the effect of salts): Franz Hofmeister's historical papers," Current Opinion in Colloid \& Interface Science, vol. 9, pp. 19-37, 2004.

[11] L. Wang, Y. Guo, P. Li, and Y. Song, "Anion-specific effects on the assembly of collagen layers mediated by magnesium ion on mica surface," The Journal of Physical Chemistry B, vol. 118, no. 2, pp. 511-518, 2014.

[12] K. D. Collins, "Ions from the Hofmeister series and osmolytes: effects on proteins in solution and in the crystallization process," Methods, vol. 34, no. 3, pp. 300-311, 2004.
[13] K. D. Collins, "Ion hydration: Implications for cellular function, polyelectrolytes, and protein crystallization," Biophysical Chemistry, vol. 119, no. 3, pp. 271-281, 2006.

[14] K. D. Collins, G. W. Neilson, and J. E. Enderby, "Ions in water: Characterizing the forces that control chemical processes and biological structure," Biophysical Chemistry, vol. 128, no. 2-3, pp. 95-104, 2007.

[15] J. Heyda, T. Hrobárik, and P. Jungwirth, "Ion-specific interactions between halides and basic amino acids in water," The Journal of Physical Chemistry A, vol. 113, no. 10, pp. 1969-1975, 2009.

[16] P. D. Yurchenco, H. Furthmayr, and A. Coritz, "Self-assembly of basement membrane collagen," Biochemistry, vol. 23, no. 8, pp. 1839-1850, 1984.

[17] D. A. Cisneros, C. Hung, C. M. Franz, and D. J. Muller, "Observing growth steps of collagen self-assembly by time-lapse high-resolution atomic force microscopy," Journal of Structural Biology, vol. 154, no. 3, pp. 232-245, 2006.

[18] G. D. Pins, D. L. Christiansen, R. Patel, and F. H. Silver, "Selfassembly of collagen fibers. Influence of fibrillar alignment and decorin on mechanical properties," Biophysical Journal, vol. 73, no. 4, pp. 2164-2172, 1997.

[19] F. H. Silver, J. W. Freeman, and G. P. Seehra, "Collagen selfassembly and the development of tendon mechanical properties," Journal of Biomechanics, vol. 36, no. 10, pp. 1529-1553, 2003.

[20] C. M. Franz and D. J. Muller, Humana Press, 736, 97-107, 2011.

[21] W. Cai, S. W. Kwok, J. P. Taulane, and M. Goodman, "Metalassisted assembly and stabilization of collagen-like triple helices," Journal of the American Chemical Society, vol. 126, no. 46, pp. 15030-15031, 2004.

[22] H. Wang, Y. Liang, H. Wang, J. Zhou, and H. Zhang, "Isolation and partial biological properties of scale collagens from grass carp (Ctenopharyngodonidellus)," Journal of Fisheries of China, vol. 36, pp. 553-561, 2012. 

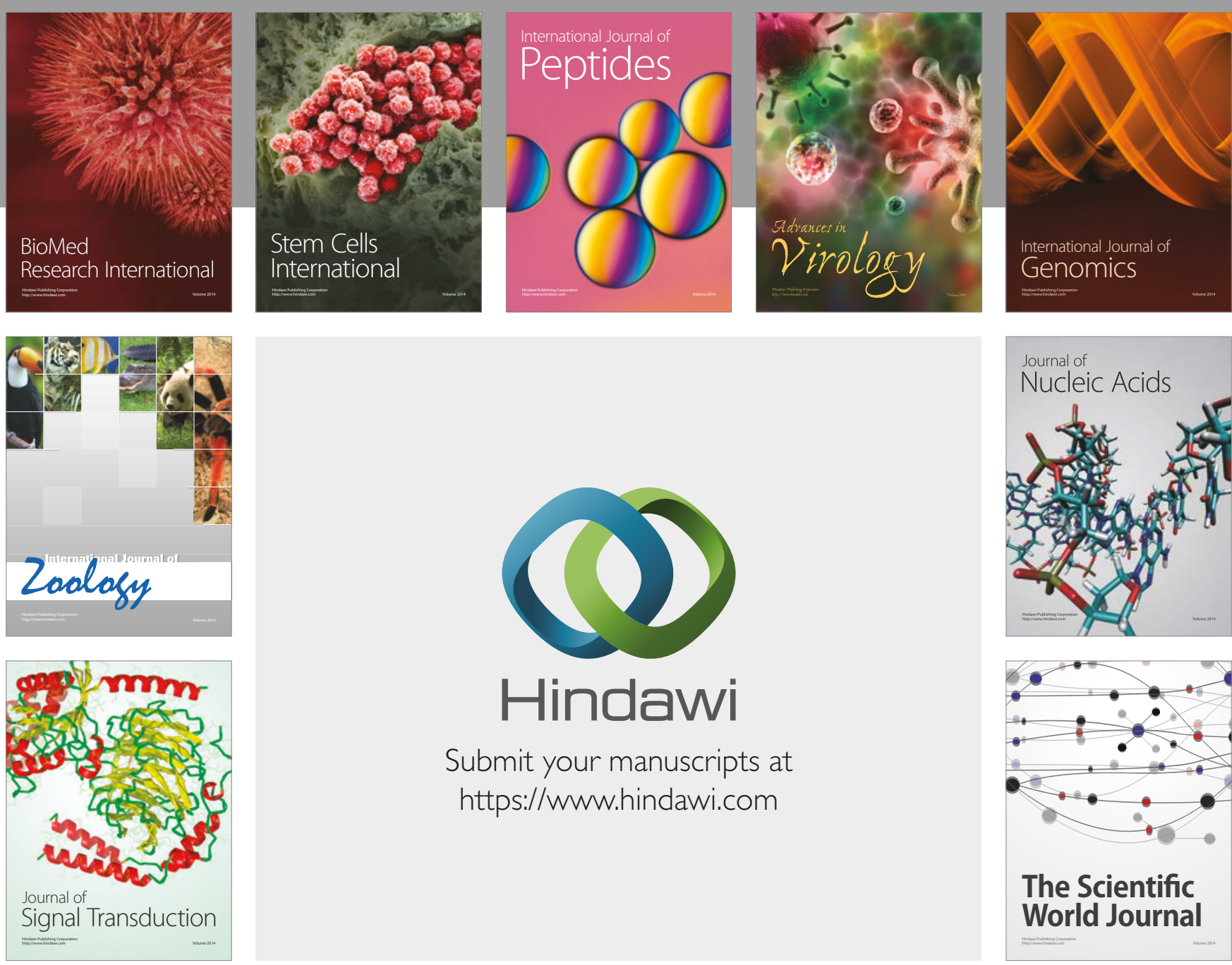

Submit your manuscripts at

https://www.hindawi.com
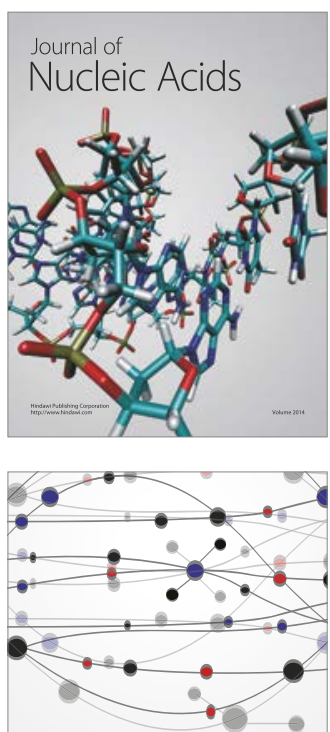

The Scientific World Journal

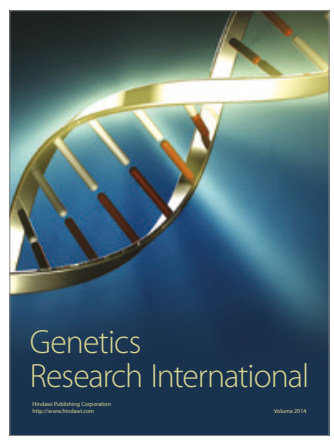

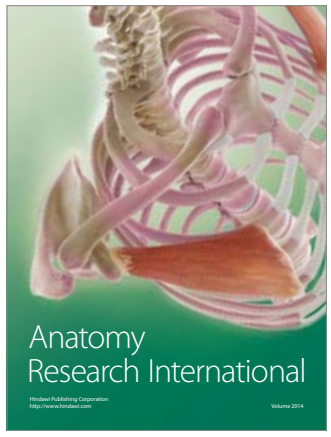

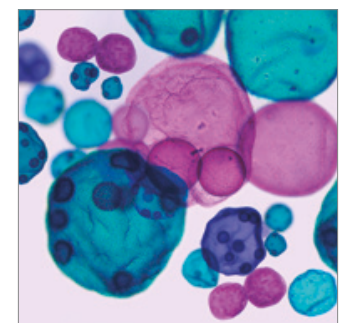

International Journal of Microbiology
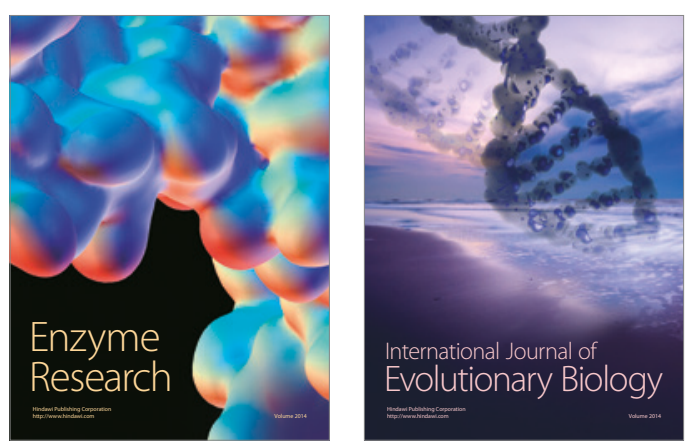
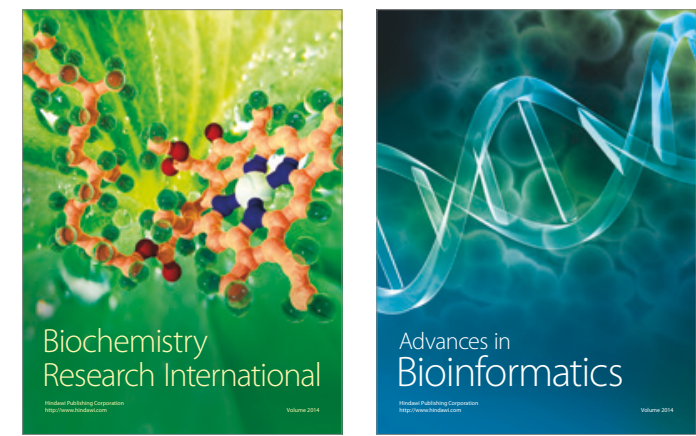

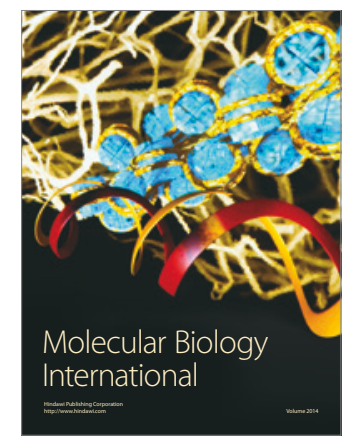

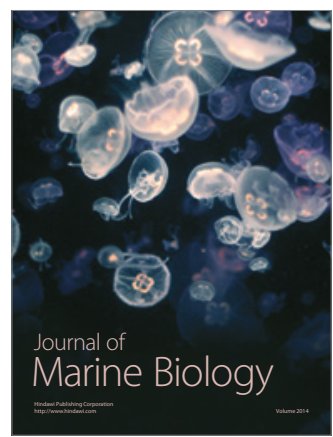

